\title{
Distinct microRNA signature in human serum and germline after childhood trauma
}

Ali Jawaid ${ }^{1,6,7 * \#}$, Marina Kunzi ${ }^{1 *}$, Mahgul Mansoor ${ }^{2}$, Zain Yar Khan ${ }^{3}$, Anooshay Abid $^{2}$, Muhammad Taha $^{2}$, Serena Rigotti ${ }^{1}$, Kristina Thumfart ${ }^{1}$, Saba Faisal ${ }^{4}$, Omar Chughtai ${ }^{5}$, Isabelle M Mansuy ${ }^{1 \#}$

${ }^{1}$ Laboratory of Neuroepigenetics, University of Zurich (UZH) and Swiss Federal Institute of Technology (ETH), Neuroscience Center Zurich, Zurich, Switzerland

2 Syed Babar Ali School of Science and Engineering, Lahore University of Management Sciences, Lahore, Pakistan

${ }^{3}$ Aga Khan University, Karachi, Pakistan

${ }^{4}$ SOS Children's Village National Office, Lahore, Pakistan

${ }^{5}$ Chughtai Laboratories Private Limited, Lahore, Pakistan

Present address:

${ }^{6}$ EMBL-Nencki Center of Excellence for Neural Plasticity and Brain Disorders (Braincity), Nencki Institute of Experimental Biology, Warsaw, Poland

${ }^{7}$ Department of Neurology, University of Texas Health Science Center, Houston, TX, USA

${ }^{*}$ Equal contribution

Running Head: Blood and germ cell miRNAs after childhood trauma

\# Correspondence to be addressed to AJ a.jawaid@nencki.edu.pl and IMM mansuy@hifo.uzh.ch 


\begin{abstract}
Traumatic experiences during childhood can persistently alter mental and physical health in humans and have been implicated in transmission of symptoms to the progeny in animal models. Molecular evidence from these models implicates epigenetic/non-genetic factors, such as microRNAs (miRNAs), in the expression of trauma-induced symptoms and their transmission to the offspring. To confirm these findings in humans, we assembled three cohorts of subjects exposed to childhood trauma and examined selected miRNAs linked to psychological and pathophysiological manifestations of childhood trauma. Children aged 712 years $(n=72$, control $n=30$ ) exposed to paternal loss and maternal separation (PLMS) exhibited increase in two miRNAs, miR-16 and miR-375 in serum and reduced level of highdensity lipoproteins (HDL) compared to control children. Comparable miRNA changes were observed in serum of adult men aged $18-25$ years $(n=13$, control $n=17)$ who had been exposed to PLMS at a young age. Finally, the same miRNAs were altered in sperm of adult men aged 21-50 years ( $n=23$, control $n=35$ ) exposed to two or more significant traumatic events in childhood, assessed retrospectively using the standardized childhood trauma questionnaire (CTQ). In vitro experiments show that regulation of these miRNA involves the HDL receptor SRB-1, suggesting a link between trauma-associated miRNAs and metabolic alterations.
\end{abstract}

Key words: childhood trauma, paternal loss and maternal separation, microRNAs, serum, sperm, seminal fluid high-density lipoproteins. 
medRxiv preprint doi: https://doi.org/10.1101/2020.08.11.20168393; this version posted August 14, 2020. The copyright holder for this preprint (which was not certified by peer review) is the author/funder, who has granted medRxiv a license to display the preprint in perpetuity.

It is made available under a CC-BY-ND 4.0 International license .

\section{Main Text}

Exposure to traumatic experiences during childhood has long-lasting effects on physical and mental health in both humans and animals ${ }^{1}$. Rodent studies have demonstrated that metabolic dysregulation and behavioral deficits induced by early life stress can also affect the offspring, sometimes across several generations ${ }^{2-5}$. The mechanisms of expression and transmission of trauma-induced symptoms are complex and likely depend on different molecular pathways and signaling cascades. Recent evidence has implicated epigenetic factors in these mechanisms. In humans and mice, changes in DNA methylation and in non-coding RNAs (ncRNA), such as microRNAs (miRNA), have been observed after trauma or stress exposure in circulation and in sperm ${ }^{6-11}$. In a mouse model of postnatal trauma (unpredictable maternal separation combined with unpredictable maternal stress, MSUS) with heritable phenotypes ${ }^{2,12}$, sperm RNA was causally involved in the transmission of metabolic and behavioral phenotypes from father to offspring or even grand-offspring ${ }^{6,7}$.

However, in humans, the evidence for the involvement of epigenetic mechanisms in the long-term sequelae of childhood trauma is still scarce and no study has examined this across age and concomitantly in body fluids and the germline. We assembled three different cohorts based in Pakistan that include children and adults with comparable exposure to childhood trauma. We chose a Pakistani population for the advantage that it is more genetically homogeneous than Western populations due to a higher level of consanguinity in the country ${ }^{13}$. This helps reduce variability and provides conditions closer to inbred mouse models. ${ }^{8}$ The first cohort includes 7-12 year old orphan children $(n=72)$ residing in three different SOS Children' Villages in Pakistan. These children have been exposed to paternal loss and maternal separation (PLMS) within the preceding year. Paternal loss was chosen as exposure because spousal death is a significant stressor in humans ${ }^{14}$. Paternal loss and abandonment by the mother resulting in adoption by the SOS village recapitulate maternal stress and separation components of a well-characterized MSUS mouse model of postnatal trauma ${ }^{2,15}$. A group of control children $(n=30)$ living with both parents was recruited from the schoolmates of PLMS children. PLMS and control children were matched for age, gender, body mass index and parental consanguinity (Supplementary Item 1). Both groups underwent thorough behavioral assessment by blinded investigators using the Center for Epidemiological Studies Depression Scale for Children (CES-DC) $)^{16}$ and the scale for anxiety-related disorders in children (SCARED) ${ }^{17}$. 
medRxiv preprint doi: https://doi.org/10.1101/2020.08.11.20168393; this version posted August 14, 2020. The copyright holder for this preprint (which was not certified by peer review) is the author/funder, who has granted medRxiv a license to display the preprint in perpetuity.

It is made available under a CC-BY-ND 4.0 International license .

The results of these assessments showed higher scores on the depression scale (Fig. 1a), and a more prevalent risk for anxiety disorders (Fig.1b) in PLMS children compared to controls. These behavioral manifestations were accompanied by lower level of high-density lipoproteins (HDL) and higher level of triglycerides (TG) compared to control children with no change in low-density lipoproteins (LDL) (Fig. 1C). Some of these alterations are comparable to those observed in adult MSUS mice and their progeny ${ }^{7,18}$.

Extra-cellular vesicles (EVs) and HDL are major carriers of circulating ncRNAs in mammals ${ }^{19}$. A large fraction of circulating miRNAs is also produced by tissues involved in lipid metabolism such as white and brown adipose tissue ${ }^{20}$. Therefore, we next investigated if the observed changes in serum HDL and lipid metabolism are associated with alterations in circulating miRNAs in PLMS children. We established a list of 9 candidate miRNAs known to be associated with traumatic stress and lipid metabolism (Supplementary Item 2). Quantitative PCR showed that six of the nine candidates were hardly detectable in serum (Ct values $>35$ ) but two of them, miR-16 and miR-375, were significantly increased in PLMS children (Fig. 1d) while miR-29a was comparable in PLMS and control children. miR-16 and miR-375 have previously been associated with regulation of behavior and metabolism (Supplementary Item 2) and are therefore relevant candidates for the phenotypes observed in PLMS children.

We next examined if the changes in miR-16 and miR-375 detected in children can also be observed in adulthood. We assembled a cohort $(n=13)$ of $18-25$ years old male subjects who had been exposed to PLMS when 7-12 years old and were hosted at the time in a SOS children Village. Control subjects were age-, gender-, and BMI-matched volunteer college students from the same demographic with no significant traumatic experience $(n=17)$. We observed that miR-16 and miR-375 were increased in the serum of PLMS adults (Fig. 1e) similar to PLMS children. These results suggest that miRNA alterations associated with childhood trauma can persist in serum until adulthood.

In mice exposed to postnatal or adult stress, miRNAs are altered in both serum and sperm $^{7,8}$. We examined if the miRNA changes that we observed in serum can also be detected in sperm of humans exposed to childhood trauma. We assembled a cohort of adult men ( $n=76$, age range: $21-50$ years; mean age: 31.2 years) who presented to a 
medRxiv preprint doi: https://doi.org/10.1101/2020.08.11.20168393; this version posted August 14, 2020. The copyright holder for this preprint (which was not certified by peer review) is the author/funder, who has granted medRxiv a license to display the preprint in perpetuity. It is made available under a CC-BY-ND 4.0 International license .

diagnostic laboratory for fertility and routine reproductive health assessments, and deposited seminal fluid for analysis. After deposition, the subjects who volunteered to be part of the study were screened for childhood trauma by blinded investigators via the childhood trauma questionnaire (CTQ). CTQ addresses six traumatic experiences (parental death, parental divorce/separation, exposure to violence or physical abuse, sexual traumatic experience, exposure to severe illness requiring hospitalization or other) before the age of 17 in adults ${ }^{21}$. Based on CTQ results, we classified the participants into three categories depending on the number of traumatic events they experienced: CTQ0 (no significant traumatic event: $n=35$ ), CTQ1 (1 significant traumatic event: $n=18$ ), CTQ2 (2 or more significant traumatic events: $n=23$ ). The perceived severity of trauma reported by the participants was comparable across different trauma types (Supplementary Item 3). In individuals with CTQ2, miR-16 and miR-375 were significantly decreased compared to individuals with no trauma (CTQ0) while miR-34c and miR-449, two miRNAs previously linked to childhood adversity ${ }^{22}$ only showed a trend towards a decrease (Figure 2a). Notably, a gradual decrease in the level of miR-34c, miR-375 and miR-449 was observed in relation with increasing traumatic events (CTQ1 and CTQ2) (Supplementary Item 4). When samples were classified into "normal" and "aberrant" based on health reference values proposed by the World Health Organization $(\mathrm{WHO})^{23}$, no difference in miRNA level could be detected between samples (Supplementary Item 5). Normal and aberrant semen samples were also equally distributed across subjects with different CTQ scores, suggesting that semen quality was comparable and did not confound the association between childhood trauma and miRNA expression (Supplementary Item 6).

We next asked if there is any relation between changes in miRNA in serum and in sperm and considered the possibility that miRNAs packaged in EVs or carried by HDL in circulation may be taken up by germ cells. EVs can be taken up by specific target cells via membrane proteins while selective HDL uptake occurs through the scavenger receptor B type 1 (SR-B1) receptor ${ }^{19,24}$. Such uptake is possible during early spermatogenesis in testes $^{25}$ when spermatogonial stem cells are in close contact with blood vessels outside the blood-testis barrier but also during sperm maturation in the epididymis when they are no longer protected by the Sertoli cell barrier within testes ${ }^{26,27}$. We isolated EVs and HDL from the seminal fluid, known to contain epidydimal EVs and HDL, collected from adults with different CTQ categories by ultracentrifugation. Candidate miRNAs in these samples were 
medRxiv preprint doi: https://doi.org/10.1101/2020.08.11.20168393; this version posted August 14, 2020. The copyright holder for this preprint (which was not certified by peer review) is the author/funder, who has granted medRxiv a license to display the preprint in perpetuity.

It is made available under a CC-BY-ND 4.0 International license .

quantified by qPCRs. None of the miRNAs were differentially regulated in EVs and HDL fractions between CTQ0 and CTQ2 groups (Figure 2b). The concentration and size of EVs and HDL particles in seminal fluid, estimated by nanotracking analysis, was comparable in the groups (Supplementary Item 7, upper panels).

Since we could not identify any link between the level of miRNAs in EVs/HDL and in seminal fluid or sperm, we hypothesized that miRNA changes detected in sperm may come from an earlier developmental stage during spermatogenesis, particularly from germ stem cells. We tested if spermatogonia-like cells (GC-1spg) can uptake EVs and/or HDL from serum in vitro. We treated GC-1 cells with serum from PLMS adults and observed that treatment increases the level of miR-375 but not miR-16 or miR-29a (Supplementary Item 8). This is consistent with the higher increase in miR-375 compared to other miRNAs in adult PLMS serum compared to controls (Figure 1e). We extracted EVs and HDL from serum of PLMS and control adults and verified their quality by nanotracking analyses. Concentration and size of particles were comparable in control and PLMS serum (Supplementary Item 7, lower panels). We then applied EVs and HDL fractions to GC-1 cells and measured miR-16, miR-34c, miR-375 or miR-449 after treatment. No difference in the level of miRNA was detected in GC-1 cells treated with EVs and HDL from control or PLMS serum. However, when HDL uptake was blocked via siRNA-mediated knockdown of the HDL receptor SR-B1 gene, SCARB1 (Figure 2c; Supplementary Item 9), treatment with EVs and HDL resulted in a decrease in miR-16 and miR-34c (trend for miR-449, no change in miR-375) in GC-1 cells, that was comparable in control and PLMS EVs/HDL samples (Figure $2 \mathrm{~d}$ ). These results suggest that SR-B1 contributes to the uptake of some miRNAs in GC-1 cells.

Together, these results show that exposure to childhood trauma is associated with alterations in some miRNAs, miR-16 and miR-375, in both serum and sperm in adult humans, and that the alterations can already be detected in the serum of children shortly after trauma. The changes are opposite in serum and sperm in adulthood, which may reflect different modes of miRNA expression and regulation in these biological samples. While miRNAs in circulation originate from peripheral tissues, miRNAs in sperm are produced in part, during spermatogenesis and are also acquired during sperm maturation. The results suggest that the miRNA changes in sperm may involve EVs and/or HDL- 
medRxiv preprint doi: https://doi.org/10.1101/2020.08.11.20168393; this version posted August 14, 2020. The copyright holder for this preprint (which was not certified by peer review) is the author/funder, who has granted medRxiv a license to display the preprint in perpetuity.

It is made available under a CC-BY-ND 4.0 International license .

derived uptake processes, consistent with previous observations that serum lipoproteins including HDL are altered after acute or chronic stress but also high-fat diet and exercise in exposed individuals and their offspring ${ }^{28}$. The observed changes in miR-16 and miR-375 are functionally relevant to the behavior and metabolic sequelae of childhood trauma and may represent useful targets for screening, prognostics and therapeutics.

\section{Acknowledgments}

This work was supported by the University of Zurich, the Swiss Federal Institute of Technology, ETH-10 15-2 and ETH-17 13-2, the Swiss National Science Foundation (NF 31003A_135715). We are grateful to Mrs. Almas Butt, Ms. Shama Khan, Mrs. Shahnaz Zaman (SOS Childrens' Villages in Lahore, Islamabad, and Multan, Pakistan), and Mrs. Kamran, Mrs. Nighat Akbar, and Mr. Muhammad Ali (SOS Hermann Gemeiner Educators School, Lahore, Pakistan), and Mr. Anwar-ul-Haq (SOS Youth Home, Lahore, Pakistan) for kindly allowing us to assess PLMS children, control children, and PLMS adults respectively. We are also thankful to Sumbal Naveed (Lahore University of Management Sciences, Lahore, Pakistan) for help in data collection, Niharika Gaur (University of Zurich) for help with molecular analyses, Naguia Haymour and Alekhya Mazumdar for help with nanotracking analysis, and the administration and staff of Chughtai Laboratories Private Limited, Pakistan for assistance with blood and seminal fluid collection procedures. Finally, we would like to extend our gratitude to Prof. Safee Ullah Chaudhry (Lahore University of Management Sciences, Lahore, Pakistan) for organizational support.

\section{Authors' contribution}

AJ contributed in study conceptualization, collection of behavioral data, sampling of biofluids, experimental design, molecular analyses, statistical analyses and visualization, manuscript writing, review and editing, project funding, and project administration and supervision. MK contributed in experimental design, molecular analyses, statistical analyses and visualization, and assisted in manuscript writing. MM, ZYK, and $A B$ contributed in collection of behavioral data, sampling of biofluids, and data mining. SR and KT assisted in molecular analyses. SF and OC contributed in collection of biofluids and project administration. IMM contributed in study conceptualization, manuscript review and editing, project funding, and project administration and supervision. All authors have reviewed and approved the final manuscript. 
medRxiv preprint doi: https://doi.org/10.1101/2020.08.11.20168393; this version posted August 14, 2020. The copyright holder for this preprint (which was not certified by peer review) is the author/funder, who has granted medRxiv a license to display the preprint in perpetuity.

$$
\text { It is made available under a CC-BY-ND } 4.0 \text { International license. }
$$




\section{References}

1. Agorastos, A. Pathophysiological trajectories and biological consequences of early life trauma. Eur. J. Psychotraumatol. 8, 1351159 (2017).

2. Franklin, T. B. et al. Epigenetic transmission of the impact of early stress across generations. Biol. Psychiatry 68, 408-15 (2010).

3. Gapp, K., Corcoba, A., van Steenwyk, G., Mansuy, I. M. \& Duarte, J. M. N. Brain metabolic alterations in mice subjected to postnatal traumatic stress and in their offspring. J. Cereb. Blood Flow Metab. 37, 2423-2432 (2017).

4. Saavedra-Rodriguez, L., Feig, L. A. \& Saavedra-Rodríguez, L. Chronic social instability induces anxiety and defective social interactions across generations. Biol. Psychiatry 73, 44-53 (2013).

5. Cordero, M. I. et al. Evidence for biological roots in the transgenerational transmission of intimate partner violence. Transl Psychiatry 2, e106 (2012).

6. Gapp, K. et al. Alterations in sperm long RNA contribute to the epigenetic inheritance of the effects of postnatal trauma. Mol. Psychiatry (2018). doi:10.1038/s41380-0180271-6

7. Gapp, K. et al. Implication of sperm RNAs in transgenerational inheritance of the effects of early trauma in mice. Nat Neurosci 17, (2014).

8. Rodgers, A. B., Morgan, C. P., Bronson, S. L., Revello, S. \& Bale, T. L. Paternal stress exposure alters sperm microRNA content and reprograms offspring HPA stress axis regulation. J. Neurosci. 33, 9003-9012 (2013).

9. Roberts, A. L. et al. Exposure to childhood abuse is associated with human sperm DNA methylation. Transl. Psychiatry 8, 194 (2018).

10. Perroud, N. et al. The Tutsi genocide and transgenerational transmission of maternal stress: epigenetics and biology of the HPA axis. World J Biol Psychiatry 15, 334-345 (2014).

11. Short, A. K. et al. Elevated paternal glucocorticoid exposure alters the small noncoding RNA profile in sperm and modifies anxiety and depressive phenotypes in the offspring. Transl. Psychiatry 6, e837-e837 (2016).

12. van Steenwyk, G., Roszkowski, M., Manuella, F., Franklin, T. B. \& Mansuy, I. M. Transgenerational inheritance of behavioral and metabolic effects of paternal exposure to traumatic stress in early postnatal life: evidence in the 4th generation. Environ. Epigenetics 4, dvy023 (2018). 
medRxiv preprint doi: https://doi.org/10.1101/2020.08.11.20168393; this version posted August 14, 2020. The copyright holder for this preprint

13. Bhinder, M. A. et al. Consanguinity: A blessing or menace at population level? Ann. Hum. Genet. 83, 214-219 (2019).

14. Prior, A. et al. Bereavement, multimorbidity and mortality: a population-based study using bereavement as an indicator of mental stress. Psychol. Med. 48, 1437-1443 (2018).

15. Gapp, K. et al. Implication of sperm RNAs in transgenerational inheritance of the effects of early trauma in mice. Nat. Neurosci. 17, 667-9 (2014).

16. Faulstich, M., Carey, M., Ruggiero, L., Enyart, P. \& Gresham, F. Assessment of depression in childhood and adolescence: an evaluation of the Center for Epidemiological Studies Depression Scale for Children (CES-DC). Am. J. Psychiatry 143, 1024-1027 (1986).

17. Birmaher, B. et al. The Screen for Child Anxiety Related Emotional Disorders (SCARED): Scale Construction and Psychometric Characteristics. J. Am. Acad. Child Adolesc. Psychiatry 36, 545-553 (1997).

18. van Steenwyk, G. et al. A novel mode of communication between blood and the germline for the inheritance of paternal experiences. bioRxiv 653865 (2019). doi:10.1101/653865

19. van Niel, G., D’Angelo, G. \& Raposo, G. Shedding light on the cell biology of extracellular vesicles. Nat. Rev. Mol. Cell Biol. 19, 213-228 (2018).

20. Thomou, T. et al. Adipose-derived circulating miRNAs regulate gene expression in other tissues. Nature 542, 450-455 (2017).

21. Fink, L., Bernstein, D., Handelsman, L., Foote, J. \& Lovejoy, M. Initial reliability and validity of the childhood trauma interview: a new multidimensional measure of childhood interpersonal trauma. Am. J. Psychiatry 152, 1329-1335 (1995).

22. Dickson, D. A. et al. Reduced levels of miRNAs 449 and 34 in sperm of mice and men exposed to early life stress. Transl. Psychiatry 8, 101 (2018).

23. Cooper, T. G. et al. World Health Organization reference values for human semen characteristics* ${ }^{*}$. Hum. Reprod. Update 16, 231-245 (2009).

24. Shen, W.-J., Asthana, S., Kraemer, F. B. \& Azhar, S. Scavenger receptor B type 1: expression, molecular regulation, and cholesterol transport function. J. Lipid Res. 59, 1114-1131 (2018).

25. Cheng, C. Y. \& Mruk, D. D. The blood-testis barrier and its implications for male contraception. Pharmacol. Rev. 64, 16-64 (2012). 
26. Sharma, U. et al. Biogenesis and function of tRNA fragments during sperm maturation and fertilization in mammals. Science 351, 391-396 (2016).

27. Reilly, J. N. et al. Characterisation of mouse epididymosomes reveals a complex profile of microRNAs and a potential mechanism for modification of the sperm epigenome. Sci. Rep. 6, 31794 (2016).

28. van Steenwyk, G., Jawaid, A. \& Mansuy, I. M. Chapter 11 - Epigenetic inheritance of metabolic signals. in Translational Epigenetics (ed. Ferguson, B. S. B. T.-N. E.) 14, 167-190 (Academic Press, 2019). 
a

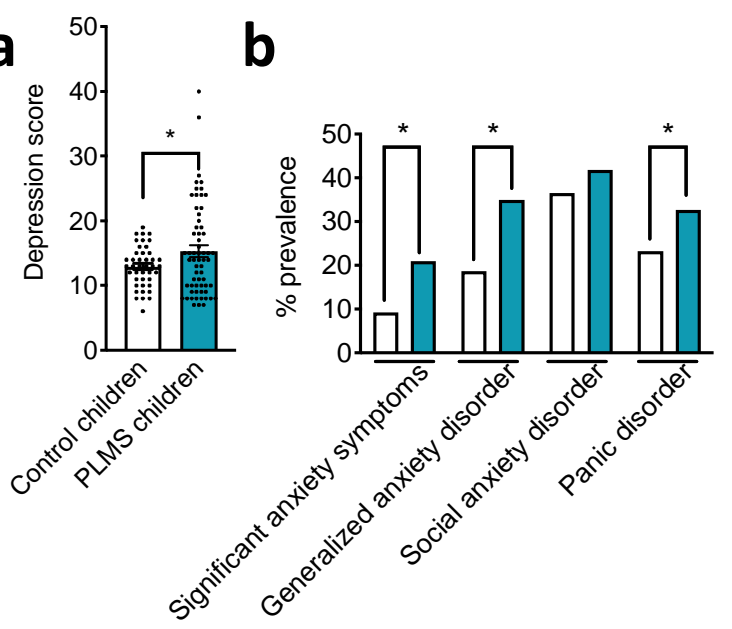

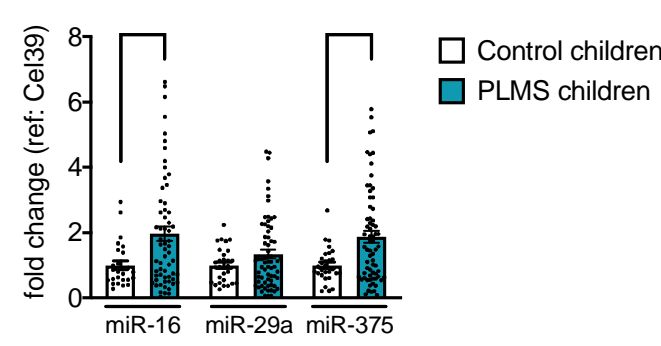

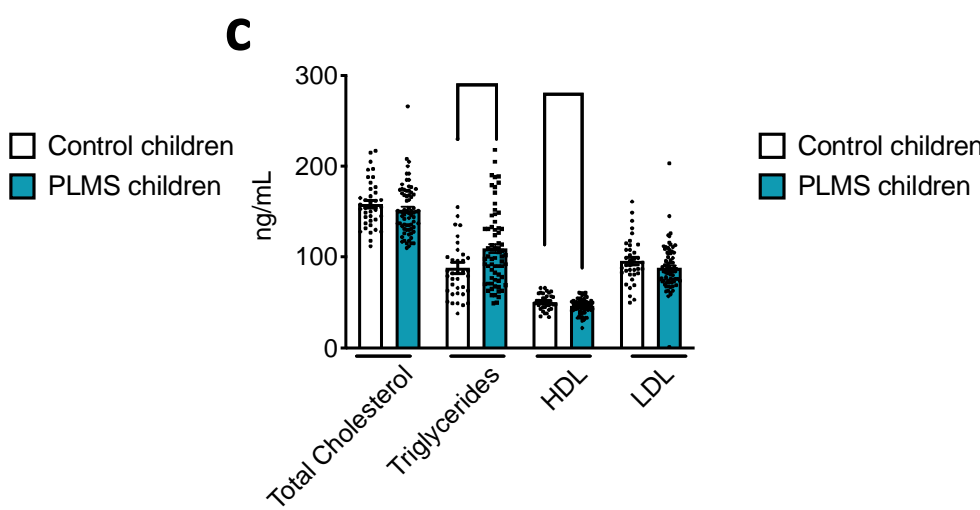

Fig. 1. Effects of PLMS on psychological health and serum miRNA expression in childhood. a) Increased depression scores in PLMS children compared to control children (PLMS children $n=72$, control children $n=30$, Welch's unpaired t-test, $p=0.0230$ ). b) Increased prevalence of anxiety disorders in PLMS children compared to control children (PLMS children $n=72$, control children $n=30$, Fisher's exact test). c) Increased triglyceride levels and lower HDL levels in PLMS children compared to controls without affecting total cholesterol and LDL levels (PLMS children $n=72$, control children $n=30$; Total Cholesterol, unpaired t-test, $p=0.2329$; Triglycerides, Mann-Whitney U-test, $\mathrm{p}=0.0053$; HDL, unpaired ttest, $\mathrm{p}=0.0091$; $L D L$, unpaired t-test, $\mathrm{p}=0.1395$ ). d) miR-16 and miR-375 are significantly increased in the serum of PLMS children compared to control children (PLMS children $\mathrm{n}=72$, control children $\mathrm{n}=30$, Mann-Whitney U-test, miR-16 $\mathrm{p}=0.0383$, miR-29a $p=0.8499$, miR-375 $p=0.0202$ ). e) miR-16, miR-29a, and miR-375 are significantly increased in the serum of adults with childhood PLMS compared to adult controls (Adult PLMS $n=13$, Adult controls $n=17$, Welch's unpaired t-test, miR-16 $p=0.0181$, miR-29a $p=0.0015$, miR-375 $p=0.0013$ ). Data represented as means \pm s.e.m., ${ }^{*} p<0.05$, ${ }^{* *} p<0.01$. All reported tests are two-tailed. All outliers removed by ROUT method $Q=1 \%$. 


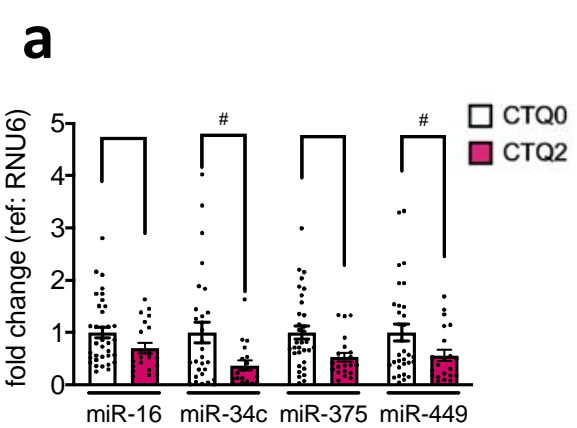

b
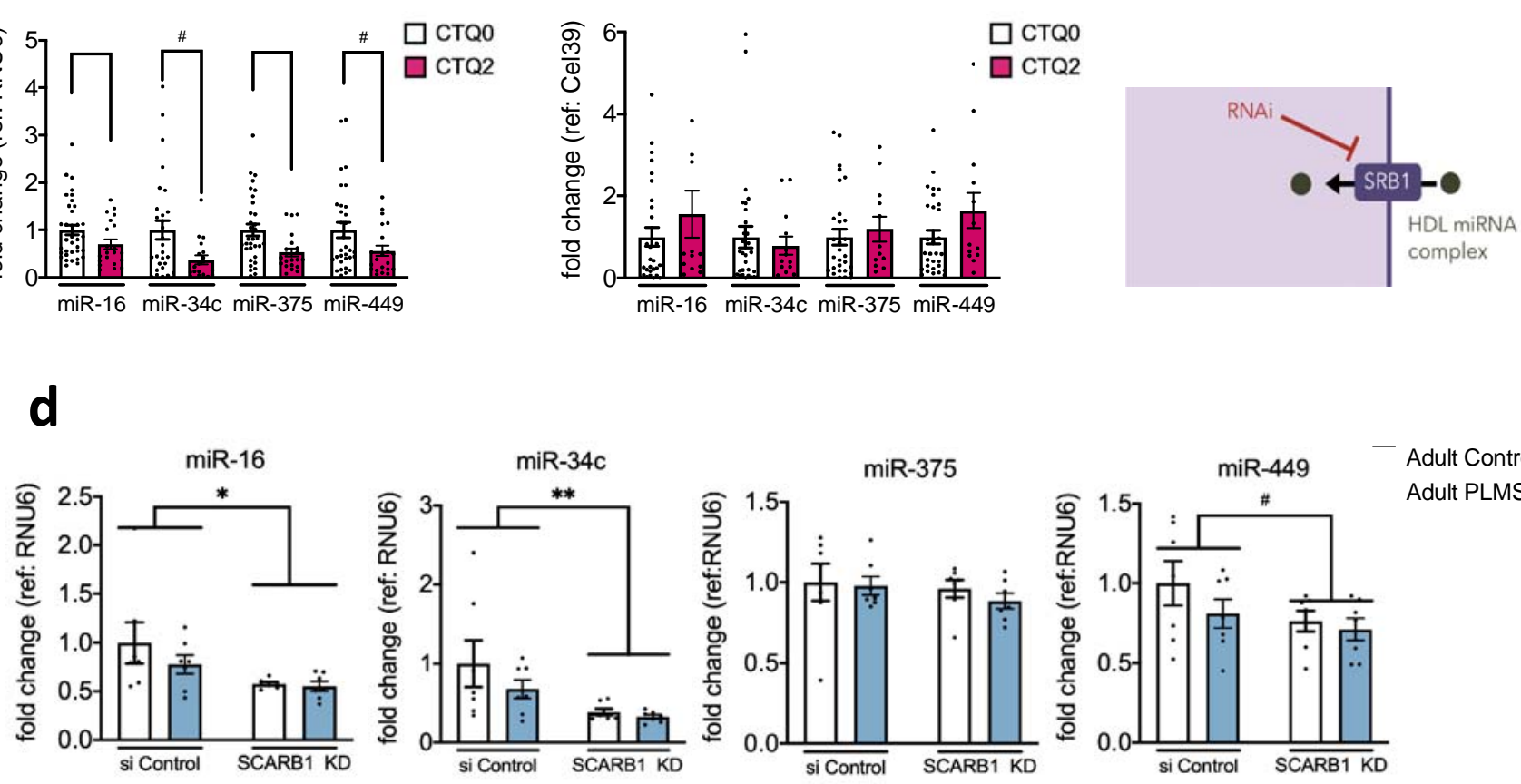

Fig.2. miRNA changes in sperm of adult men exposed to childhood trauma. a) miR-16 and miR-375 are decreased in sperm of adults with two or more traumatic experiences (CTQ2) compared to adults with no childhood trauma exposure (CTQ0) (CTQ2 $n=23$, CTQ0 $n=35$, Mann-Whitney U-test, miR-16 $p=0.0411$, miR-34c $p=0.0518$, miR-375 $p=0.0077$, miR-449 $p=0.528$ ). b) Candidate miRNAs are not significantly different in EVs and HDL isolated from seminal fluid of subjects from CTQ2 and CTQ0 groups (CTQ2 $n=14$, CTQ0 $n=27$, Mann-Whitney U-test, miR-16 $p=0.2455$, miR-34c $p=0.7605$, miR$375 p=0.3559$, miR-449 $p=0.1281$ ). c) Schematic of the uptake of extracellular miRNAs into recipient cells through the scavenger receptor SR-B1 along with inhibition of this mode of uptake through siRNA-mediated knock-down d) GC-1 cells transfected either with siRNA targeting SCARB1 or a control siRNA $24 \mathrm{~h}$ prior to treatment with serum miRNA-carriers of adult control or adult PLMS for $24 \mathrm{~h}$. Knockdown of SCARB1 results in significantly lower miR-16 and miR-34c (Adult Controls $n=7$, adult PLMS $n=7$, two-way ANOVA, miR-16, interaction $p=0.4153$, row-factor $p=0.0123$, column-factor $p=0.3123$, miR-34c, interaction $p=0.4232$, row-factor $p=0.0063$, column-factor $p=0.2434$, miR-375 interaction $p=0.7163$, row-factor $p=0.3741$, column-factor $p=0.5097$, miR-449 interaction $p=0.4757$, row-factor $p=0.0908$, column-factor $p=0.2184$ ). Data represented as means \pm 
medRxiv preprint doi: https://doi.org/10.1101/2020.08.11.20168393; this version posted August 14, 2020. The copyright holder for this preprint (which was not certified by peer review) is the author/funder, who has granted medRxiv a license to display the preprint in perpetuity. It is made available under a CC-BY-ND 4.0 International license .

s.e.m., ${ }^{*} p<0.05,{ }^{* *} p<0.01$. All reported tests are two-tailed. All outliers removed by ROUT method $\mathrm{Q}=1 \%$. 